\title{
Hubungan Pemahaman Materi Thaharah dengan Kebiasaan Perilaku Hidup Bersih dan Sehat (PHBS) Pada Siswa di MTs Darul Muttaqien, Bogor
}

\author{
${ }^{1}$ Ilma Sabila, ${ }^{2}$ Mae'munah Sa'diyah \\ ${ }^{12}$ Universitas Ibn Khaldun Bogor \\ Email: ilmasabila97@gmail.com
}

\begin{abstract}
Thaharah is one of the syariah in Islam which teaches its adherents about cleanliness as a form of obedience to the provisions that Allah has commanded. PHBS is a movement, attitude, knowledge, and pro-active action whose aim to maintain and prevent from disease. This study aims to determine the relationship between understanding thaharah material and hygiene and healthy living habits (PHBS). The research method used in this research is correlational quantitative method. The sample in this study were students of class VIII MTs Darul Muttaqien Bogor Regency. The data collection techniques used in this study were questionnaires and tests. The instruments used in this study were 15 test items and 13 questionnaires. The results of the study through correlational tests showed that there was a significant relationship between understanding thaharah material and clean and healthy living habits (PHBS). The correlational test shows a significance value of sig. (2-tailed) $0.0000<0.05$ with a Pearson correlation value of 0.878 so that it is interpreted that the relationship between the two is strong.
\end{abstract}

Keywords: Thaharah, Habbit, PHBS

\section{Pendahuluan}

Islam merupakan agama sempurna yang sangat memperhatikan setiap sisi kehidupan para penganutnya. Hal ini tercermin dalam materi mengenai kebersihan atau Thaharah yang diajarkan di dalam Islam. Thaharah ini merupakan aturan di dalam Islam yang berarti menjaga kebersihan sebagai ketaatan atas ketentuan yang telah disyariatkan oleh Islam.

Islam juga telah mengatur masalah kebersihan dari mulai bangun tidur sampai tidur kembali. Tidak ada agama lain yang memperhatikan aturan sedetail Islam mengatur kehidupan setiap umatnya. Salah satu yang telah diatur dalam hukum Islam adalah disyariatkan umat Islam untuk memperhatikan pentingnya menjaga kebersihan demi kesehatan diri sendiri. Sehingga dalam hal ini seorang muslim dianjurkan agar memperhatikan kebersihan diri sendiri dan lingkungannya ${ }^{1}$.

Thaharah didefinisikan sebagai bersuci dari hadas, baik hadas besar maupun hadas kecil dan bersuci dari najis yang meliputi badan, pakaian, tempat dan benda-benda yang terbawa atau terdapat pada tubuh ${ }^{2}$. Sementara Al-Munawwir berpendapat bahwa thaharah dari sudut etimologis menunjuk makna pokok bersih atau hilangnya kotoran. Dan dari sudut etimologi berarti suci, bersih, menjauhkan, mensucikan, dan membersihkan kotoran atau najis dari lain-lain³.

1 Al-Mahfani Dkk, Kitab Lengkap Panduan Shalat, Jakarta: Wabyu Qolbu, 2016, bal. 24

2 M. Said Alamsyah Dkk, Meningkatkan Minat Belajar Thaharah Dalam Membersibkan Najis dan Hadas untuk tingkat Media Pop Up Book, Jurnal FSD Vol. 1 No. 1, 2020, hal. 117

3 Ahmad Mujahid Dkk, Thaharah Labir dan Batin Dalam Al-Qur'an, Jural Ar-Risalah Vol. 19 No. 2, 2019, hal. 199 
Seorang muslim sudah sepatutnya memperhatikan penampilannya agar terlihat bersih dan rapih. Sebagaimana jika kita ingin bertemu seorang presiden sudah barang tentu kita harus memantaskan dengan berpenampilan bersih dan rapih. Jika bertemu dengan makhluk-Nya saja harus berpenampilan rapi, bagaimana jika akan bertemu dengan Pencipta-Nya. Thaharah didalam Islam dapat memberikan berbagai macam manfaat. Islam secara komprehensif mengemukakan bahwa manfaat dari bersuci diantaranya adalah dapat menumbuhkan berbagai macam sifat, sikap, nilai serta pesan yang akan berpengaruh pada perilaku individu. Disamping itu, thaharah juga berpengaruh terhadap berbagai macam aspek seperti muamalah, akhlak, akidah dan lain sebagainya ${ }^{4}$.

PHBS atau Perilaku Hidup Bersih dan Sehat merupakan suatu gerakan, sikap, pengetahuan, dan tindakan proaktif yang tujuannya untuk memelihara serta mencegah diri dari terserangnya penyakit. Selain itu Perilaku Hidup Bersih dan Sehat dapat melindungi diri dari berbagai macam penyakit serta memiliki peran aktif dalam gerakan masyarakat sehat ${ }^{5}$. Sedangkan meurut Proverawati PHBS merupakan cerminan pola hidup keluarga yang selalu memperhatikan dan menjaga seluruh anggota keluarga ${ }^{6}$.

PHBS adalah semua perilaku kesehatan yang dilakukan atas kesadaran sehingga anggota keluarga atau keluarga dapat menolong dirinya sendiri dibidang kesehatan dan dapat berperan aktif dalam kegiatan-kegiatan kesehatan di masyarakat. Dan PHBS merupakan salah satu upaya preventif atau pencegahan terhadap suatu penyakit dan promotif atau peningkatan derajat kesehatan pada seseorang, sehingga dapat dikatakan sebagai pilar Indonesia Sehat 2020.

Sekolah merupakan institusi pendidikan yang menjadi target PHBS, sehingga penerapan prilaku tersebut menjadi lebih baik. Kurangnya pelaksanaan PHBS di lingkungan sekolah dapat menyebabkan dampak buruk bagi siswa yaitu kurang nyamannya suasana belajar dan menurunnya semangat serta prestasi belajar siswa ${ }^{7}$. Indikator PHBS di lingkungan sekolah ada 8 yaitu : mencuci tangan menggunakan air mengalir dan memakai sabun, mengkonsumsi jajanan sehat di kantin sekolah, menggunakan fasilitas jamban bersih dan sehat, melaksanakan olahraga secara teratur, memberantas jentik nyamuk di sekolah, mengukur berat badan dan tinggi badan, membuang sampah pada tempat yang telah disediakan dan tidak merokok di sekolah ${ }^{8}$.

Manfaat PHBS di sekolah adalah terciptanya sekolah yang bersih dan sehat sehingga peserta didik, guru dan masyarakat lingkungan sekolah terlindungi dari berbagai gangguan dan ancaman penyakit, meningkatnya semangat proses belajar mengajar yang

${ }^{4}$ Ahmad M.S, Thaharah Makna Zawahir dan Bawathin Dalam Bersuci, Mizan: Jurnal Ilmu Syariah Vol. 2 No. 1, 2014, hal. 57

5 Tim Field Fakultas Kedokteran UNS, Komunikasi Informasi Edukasi PHBS, Surakarta: Fakultas Kedokteran Universitas Sebelas Maret, 2013, hal. 3

${ }^{6}$ Julianti R., Pelaksanaan PHBS di Lingkungan Sekolah, Jurnal Ilmiah Potensia, Vol. 3 No. 2, 2018, hal 13

${ }^{7}$ Lina H.P, Perilaku Hidup Bersih dan Sehat Siswa di SDN 42 Korong Gadang Kecamatan Kuranji Padang, Jurnal Promkes, Vol. 4 No. 1, 2016, hal. 93

8 Andriansyah Y., Penyuluban dan Praktik PHBS dalam mewujudkan masyarakat desa peduli sehat, Jurnal Inovasi dan kewirausahaan, 2013, hal. 48 
berdampak pada prestasi belajar siswa dan merupakan kegiatan memberdayakan siswa, guru dan masyarakat di sekolah untuk melakukan pola hidup sehat'.

Penerapan PHBS di sekolah merupakan kebutuhan mutlak seiring munculnya penyakit yang sering menyerang anak usia sekolah. Siswa merupakan sasaran yang sangat efektif dalam hal merubah perilaku dan kebiasaan hidup sehat. Selain itu siswa atau usia sekolah merupakan usia yang sangat rawan akan masalah kesehatan sehingga dapat mempengaruhi proses pertumbuhan dan perkembangan serta prestasi belajar.

Pembinaan PHBS di sekolah dapat diberikan tiga kelompok sasaran PHBS yaitu: sasaran primer, sasaran sekunder dan sasaran tersier. PHBS di sekolah adalah upaya untuk memberdayakan siswa, guru dan masyarakat lingkungan sekolah agar tahu dan mampu mempraktekan PHBS dan berperan aktif dalam mewujudkan sekolah sehat ${ }^{10}$. PHBS di Sekolah juga merupakan sekumpulan perilaku yang dipraktikan oleh siswa, guru dan masyarakat lingkungan sekolah atas dasar kesadaran secara mandiri yang mampu mencegah penyakit, meningkatkan kesehatan, serta berperan aktif dalam mewujudkan lingkungan sehat

Idealnya, siswa yang telah menerima materi thaharah dapat menerapkan kebiasaan Perilaku Hidup Bersih dan Sehat di lingkungan sekolah dengan baik. Karena hal ini pun didukung oleh program kebersihan di sekolah diantaranya: pertama, tersedianya jadwal piket di setiap kelas, yang mana siswa memiliki tanggung jawab tehadap kebersihan kelas. Kedua, ketersediaan tempat sampah di lingkungan kelas. Ketiga, keadaan toilet yang cukup baik, hal ini dapat dilihat dari ketersediaan tempat sampah dan air bersih.

Sejalan dengan Penelitian dilakukan oleh Silvy Agustiningrum (2018), menyatakan bahwa berdasarkan penyajian dan analisis uji statistik dapat diperoleh kesimpulan bahwa ada pengaruh yang signifikan pada pembelajan fikih Thaharah terhadap kemampuan praktek bersuci siswa SMP Plus Arroudhoh Sedati. Hal ini terbukti dengan diterimanya Hi potesis Kerja $\left(\mathrm{H}_{2}\right)$ dan ditolaknya Hipotesis Nihil $\left(\mathrm{H}_{\mathrm{o}}\right)$. diperoleh R Square sebesar 0,489, artinya 48,9\% kemampuan praktik bersuci siswa dapat dipengaruhi oleh faktor pembelajaran fikih Thaharah, sedangkan sisanya 51,1 \% dipengaruhi oleh faktor lain yang tidak terdapat dalam penelitian. Dan untuk taraf signifikasinya berada dalam kategori kuat yaitu berada pada interval 0,60-0,799.

Sementara penelitian yang dilakukan oleh peneliti membahas tentang hubungan pemahaman materi thaharah dengan kebiasaan perilaku hidup bersih dan sehat. Persamaan antara kedua penelitian adalah keduanya membahas hubungan materi dengan hidup bersih dan sehat, subjek penelitian merupakan sisswa tingkat tsanawiyah atau menengah pertama. Sementara, perbedaan dari kedua penelitian ini adalah penelitian yang dilakukan oleh Silvy Agustinningrum (2018) hanya memfokuskan materi thaharah dengan praktek bersuci. Presentase keberhasilan diambil hanya saat praktek bersuci bukan pada kehidupan sehari-hari. Sementara penelitian yang dilakukan oleh Ilma Sabila (2020) memfokuskan hubungan materi thaharah dengan kebiasaan perilaku hidup bersih

9 Tanjung N., Hubungan Pengetabuan dan Sikap Siswa Tentang Perilaku Hidup Bersib dan Sehat dengan tindakan PHBS di SD Swasta Luther Kecamatan Siatas Barita Tapanuli Utara tabun 2013, Jural Mutiara Kesehatan Masyarakat, Vol. 1 No. 1, 2016, hal. 50

10 Aswadi Dkk, PHBS pada siswa-siswi SDK Rita Pada Kecamatan Kota Komba Kabupaten Manggarai Timur Provinsi Nusa Tenggara Timur, Al-Sihah: Public Health Science Jurnal Vol. 9 No. 2, 2017, hal. 187 
dan sehat. Jadi pmanresentase keberhasilan diambil dari angket yang disebar mengenai kebiasaan perilaku hidup bersih dan sehat

Permasalahan dalam penelitian ini adalah untuk mengetahui pemahaman materi thaharah, penerapan perilaku hidup bersih dan sehat dan hubungan antara pemahaman materi thaharah dengan penerapan perilaku hidup bersih dan sehat. Tujuan dari penelitian ini adalah untuk mengetahui pemahaman siswa mengenai materi thaharah, untuk mengetahui bagaimana penerapan PHBS siswa di MTs Darul Muttaqien dan untuk mengetahui hubungan yang signifikan antara pemahaman materi thaharah dengan kebiasaan PHBS di MTs Darul Muttaqien. Berdasarkan hipotesis penelitian yang dilakukan oleh peneliti terdapat hubungan antara materi thaharah dengan kebiasaan perilaku hidup bersih dan sehat di sekolah pada siswa kelas VIII.

\section{Metode Penelitian}

Pendekatan yang diterapkan pada penelitian ini adalah pendekatan kuantitatif. Penelitian kuantitatif merupakan penelitian yang mengandung kaidah-kaidah ilmiah seperti konkrit/empiris, obyektif, terukur, rasional dan sistematis. Penelitian kuantitatif merupakan penelitian yang datanya berupa angka-angka dan analisis menggunakan statistic. ${ }^{11}$ Penelitian ini menggunakan metode korelasional, penelitian ini mengkaji dua variabel. Dalam penelitian ini, yang menjadi variabel bebas (independent) adalah Pemahaman Materi Thaharah (Variabel X) dan yang menjadi variabel terikat (dependent) adalah Perilaku Hidup Bersih dan Sehat (PHBS) (Variabel Y). Penelitian ini dilaksanakan di Madrasah Tsanawiyah Darul Muttaqien yang berlokasi di Jalan Raya Parung-Bogor KM 41, Jabon Mekar, Parung Bogor Jawa Barat. Penelitian ini dilaksanakan pada bulan September 2020 dan penelitian ini telah dilakukan pada siswa kelas VIII MTs Darul Muttaqien. Untuk mencari dan mengumpulkan data dalam penelitian ini, peneliti menggunakan beberapa cara dan teknik dalam pengumpulan data yaitu angket dan tes. Sementara, untuk teknik analisis data peneliti menggunakan uji normalitas menggunakan uji kolmogrof-smirnov test yang dilakukan dengan bantuan spss 22.0 for windows dan uji korelasional juga menggunakan spss 22.0 for windows.

\section{Hasil dan Pembahasan}

Berdasarkan penelitian yang telah dilakukan oleh penulis ditemukan hasil sebagai berikut:

\section{Uji Normalitas}

Tabel 1. Uji Normalitas

\begin{tabular}{|l|l|r|}
\hline \multicolumn{2}{|c|}{ One-Sample Kolmogorov-Smirnov Test } \\
\hline $\mathrm{N}$ & \multicolumn{1}{|c|}{ Unstandardized Residual } \\
\hline \multirow{2}{*}{ Normal Parameters ${ }^{\mathrm{a}, \mathrm{b}}$} & Mean & .0000000 \\
\cline { 2 - 3 } & Std. Deviation & 1.97802059 \\
\hline \multirow{2}{*}{ Most Extreme Differences } & Absolute & .0196 \\
\cline { 2 - 3 } & Positive & .088 \\
\cline { 2 - 3 } & Negative & -.082 \\
\hline Test Statistic & .196 \\
\hline Asymp. Sig. (2-tailed) & $.200^{\mathrm{c}, \mathrm{d}}$ \\
\hline
\end{tabular}

${ }^{11}$ Sugiyono, Metode Penelitian Kuantitatif, Kualitatif dan R\&D, Bandung: Alfabeta, 2016, hal. 7 
a. Test distribution is Normal.

b. Calculated from data.

c. Lilliefors Significance Correction.

$\mathrm{d}$. This is a lower bound of the true significance.

Dari Tabel diatas menunjukan nilai tes kolmogorov-smirnov dengan nilai signifikan 0,200 lebih besar dari 0,05, sehingga dapat disimpulkan data yang digunakan berdistribusi normal.

\section{Deskripsi Data Pemahaman Materi Thaharah}

Untuk mengetahui hubungan pemahaman materi thaharah dengan kebiasaan perilaku hidup bersih dan sehat (PHBS) di Mts Darul Muttaqien, peneliti menggunakan data yang diperoleh dari hasil penyebaran tes yaitu, dengan menyebarkan secara langsung kepada siswa kelas VIII MTs Darul Muttaqien agar menghasilkan data yang relevan. Berikut adalah tabel deskripsi data pemahaman materi thaharah di kelas VIII di MTs Darul Muttaqien :

Tabel 2. Data Hasil Tes Pemahaman Materi Thaharah

\begin{tabular}{|c|c|c|}
\hline No & Nama & Skor \\
\hline 1 & Adiba Aulia Putri & 80 \\
\hline 2 & Adinda Deswita Maharani & 67 \\
\hline 3 & Anggun Zahra Kinanti & 73 \\
\hline 4 & Desnita Nur Halisa & 87 \\
\hline 5 & Dhiya Najma Sarah Hisaana & 80 \\
\hline 6 & Fachira Selima & 87 \\
\hline 7 & Farah Fitria Azzahra & 67 \\
\hline 8 & Fathya Syira Safina & 80 \\
\hline 9 & Ginayaturohmah & 73 \\
\hline 10 & Hannisya Amira Hutasuhut & 87 \\
\hline 11 & Humaira Fayza Mufidah & 80 \\
\hline 12 & Indah Pratiwi & 73 \\
\hline 13 & Izyani Khaliza Nurfadilla & 67 \\
\hline 14 & Mashya Alesha Mulyantoro & 93 \\
\hline 15 & Nabila Putri Rihwania & 73 \\
\hline 16 & Nadiya Putri Mulyantina & 87 \\
\hline 17 & Naila Fakhriyah & 93 \\
\hline 18 & Najwah Chairunnisa & 80 \\
\hline 19 & Natasha Della Puspita & 67 \\
\hline 20 & Nazila Zakia Melati Fayyad & 73 \\
\hline 21 & Nazla Syafitri Awliyadi & 80 \\
\hline 22 & Nuha Alayya Ramadhani & 87 \\
\hline 23 & Rajni Kamila & 67 \\
\hline 24 & Rarasati Az zura Ayuningtyastuti & 93 \\
\hline 25 & Riva Nada Nisrina & 73 \\
\hline 26 & Thanya Azura Rianto & 93 \\
\hline 27 & Yulia Widia Ningrum & 80 \\
\hline 28 & Zahra Arafha Maulida & 67 \\
\hline 29 & Zahwa Auglia Safiqah & 93 \\
\hline 30 & Zalfa Rifdah Kholilah & 87 \\
\hline \multicolumn{2}{|r|}{ Nilai Minimum } & 67 \\
\hline \multicolumn{2}{|r|}{ Nilai Maksimum } & 93 \\
\hline \multicolumn{2}{|r|}{ Rata-rata } & 80 \\
\hline
\end{tabular}


Pemahaman siswa mengenai materi Thaharah di MTs Darul Muttaqien dapat dikatakan memuaskan. Hal ini dilihat melalui data variabel X (Pemahaman materi Thaharah) yang menunjukan nilai rata-rata tes sebesar 80 dengan nilai maksimum sebesar 93.

\section{Deskripsi Data kebiasaan perilaku hidup bersih dan sehat (PHBS) di MTs Darul Muttaqien}

Untuk mengetahui hubungan pemahaman materi thaharah dengan kebiasaan perilaku hidup bersih dan sehat (PHBS) di Mts Darul Muttaqien, peneliti menggunakan data yang diperoleh dari hasil penyebaran angket yaitu, dengan menyebarkan secara langsung kepada siswa kelas VIII MTs Darul Muttaqien agar menghasilkan data yang relevan. Berikut adalah tabel deskripsi data kebiasaan perilaku hidup bersih dan sehat di kelas VIII di MTs Darul Muttaqien :

Tabel 3. Rekapitulasi Hasil Skor Angket tentang Kebiasaan PHBS (Y)

\begin{tabular}{|c|c|c|c|c|c|c|c|c|c|c|c|}
\hline \multirow[t]{2}{*}{ No } & \multirow[t]{2}{*}{ Pernyataan } & \multicolumn{2}{|c|}{\begin{tabular}{c|} 
Sangat \\
Tidak Setuju
\end{tabular}} & \multicolumn{2}{|c|}{ Tidak Setuju } & \multicolumn{2}{|c|}{ Ragu-Ragu } & \multicolumn{2}{|c|}{ Setuju } & \multicolumn{2}{|c|}{$\begin{array}{l}\text { Sangat } \\
\text { Setuju }\end{array}$} \\
\hline & & $\mathbf{F}$ & $\%$ & $\mathbf{F}$ & $\%$ & $\mathbf{F}$ & $\%$ & $\mathbf{F}$ & $\%$ & $\mathbf{F}$ & $\%$ \\
\hline 1 & $\begin{array}{l}\text { Mencuci tangan sebelum } \\
\text { makan terlebih dahulu }\end{array}$ & 0 & $0 \%$ & 1 & $3 \%$ & 1 & $3 \%$ & 9 & $30 \%$ & 19 & $63 \%$ \\
\hline 2 & $\begin{array}{l}\text { Abai dalam memilih jajanan } \\
\text { dikantin sekolah }\end{array}$ & 13 & $43 \%$ & 11 & $37 \%$ & 5 & $17 \%$ & 1 & $3 \%$ & 0 & $0 \%$ \\
\hline 3 & $\begin{array}{l}\text { Membuang pembalut } \\
\text { kedalam kloset }\end{array}$ & 21 & $70 \%$ & 8 & $27 \%$ & 0 & $0 \%$ & 0 & $0 \%$ & 1 & $3 \%$ \\
\hline 4 & Bolos pada saat jam olahraga & 20 & $67 \%$ & 8 & $27 \%$ & 0 & $0 \%$ & 0 & $0 \%$ & 2 & $3 \%$ \\
\hline 5 & $\begin{array}{l}\text { Tidak membiarkan genangan } \\
\text { air di kamar mandi }\end{array}$ & 1 & $3 \%$ & 0 & $0 \%$ & 5 & $17 \%$ & 11 & $37 \%$ & 13 & $43 \%$ \\
\hline 6 & $\begin{array}{l}\text { Membuang air sisa pel an } \\
\text { setiap selesai piket kelas }\end{array}$ & 0 & $0 \%$ & 0 & $0 \%$ & 2 & $7 \%$ & 11 & $37 \%$ & 17 & $57 \%$ \\
\hline 7 & $\begin{array}{l}\text { Menimbang berat badan } \\
\text { secara berkala }\end{array}$ & 0 & $0 \%$ & 0 & $0 \%$ & 4 & $13 \%$ & 10 & $33 \%$ & 15 & $50 \%$ \\
\hline 8 & $\begin{array}{l}\text { Mengukur tinggi badan } \\
\text { secara teratur }\end{array}$ & 0 & $0 \%$ & 1 & $3 \%$ & 3 & $10 \%$ & 13 & $43 \%$ & 13 & $43 \%$ \\
\hline 9 & $\begin{array}{l}\text { Abai terhadap perkembangan } \\
\text { berat badan }\end{array}$ & 12 & $40 \%$ & 15 & $50 \%$ & 2 & $7 \%$ & 1 & $3 \%$ & 0 & $0 \%$ \\
\hline 10 & $\begin{array}{l}\text { Tidak peduli lingkungan } \\
\text { kelas yang kotor }\end{array}$ & 19 & $63 \%$ & 11 & $37 \%$ & 0 & $0 \%$ & 0 & $0 \%$ & 0 & $0 \%$ \\
\hline 11 & $\begin{array}{l}\text { Melaksanakan piket kelas } \\
\text { dengan baik }\end{array}$ & 0 & $0 \%$ & 0 & $0 \%$ & 0 & $0 \%$ & 10 & $33 \%$ & 20 & $67 \%$ \\
\hline 12 & $\begin{array}{l}\text { Membuang sampah pada } \\
\text { tempatnya }\end{array}$ & 0 & $0 \%$ & 0 & $0 \%$ & 0 & $0 \%$ & 12 & $40 \%$ & 18 & $60 \%$ \\
\hline 13 & $\begin{array}{lll}\text { Membuang } & \text { sampah } & \text { di } \\
\text { kolong meja } & & \\
\end{array}$ & 18 & $60 \%$ & 11 & $17 \%$ & 1 & $3 \%$ & 0 & $0 \%$ & 0 & $0 \%$ \\
\hline & Total & 30 & $100 \%$ & 30 & $100 \%$ & 30 & $100 \%$ & 30 & $100 \%$ & 30 & $100 \%$ \\
\hline
\end{tabular}

Penerapan PHBS siswa di MTs Darul Muttaqien dapat dikatakan memuaskan. Hal ini dilihat dari data angket variabel y mengenai Kebiasaan Perilaku Hidup Bersih dan Sehat dengan skor rata-rata 57,8 dengan nilai maksimal 65. 


\section{Korelasi antara pemahaman materi thaharah dan kebiasaan perilaku hidup bersih dan sehat siswa kelas VIII di MTs Darul Muttaqien}

Untuk mengetahui korelasi antara pemahaman materi thaharah dan perilaku hidup bersih dan sehat (PHBS) siswa kelas VIII MTs Darul Muttaqien, peneliti menguji korelasi antara dua variabel tersebut menggunakan spss. Hasil uji korelasi terdapat pada table berikut ini.

Tabel 4. Hasil Uji Korelasi

\begin{tabular}{|l|l|r|r|}
\hline \multicolumn{2}{|c|}{ Correlations } \\
\hline \multirow{4}{*}{ THAHARAH } & THAHARAH & \multicolumn{1}{c|}{ PHBS } \\
\hline \multirow{5}{*}{ PHBS } & Pearson Correlation & 1 & $.878^{*}$ \\
\cline { 2 - 4 } & Sig. (2-tailed) & 30 & .000 \\
\cline { 2 - 4 } & $\mathrm{N}$ & $.878^{*}$ & 30 \\
\hline & Pearson Correlation & .000 & 1 \\
\cline { 2 - 4 } & Sig. (2-tailed) & 30 & 30 \\
\cline { 2 - 4 } & $\mathrm{N}$ & \multicolumn{2}{|}{} \\
\hline \multirow{2}{*}{ *. Correlation is significant at the 0.05 level (2-tailed). }
\end{tabular}

Kriteria pengujian adalah sebagai berikut: Ha ditolak, jika nilai sig. (2-tailed) $<0,05$

Ha diterima, jika nilai sig. (2-tailed) $>0,05$

Tabel 5. Interpretasi Korelasi Pearson

\begin{tabular}{|c|c|}
\hline Besarnya Nilai & Interprestasi \\
\hline $0,00-0,20$ & Tidak \\
\hline $0,20-0,40$ & Kurang \\
\hline $0,40-0,70$ & Sedang \\
\hline $0,70-0,90$ & Kuat \\
\hline $0,90-1000$ & Sangat kuat \\
\hline
\end{tabular}

Berdasarkan pengujian melalui korelasi pearson diketahui nilai sig. (2-tailed) sebesar $0,0000<0,05$ sehingga dapat disimpulkan terdapat hubungan yang signifikan antara Pemahaman materi Thaharah dengan kebiasaan perilaku hidup bersih dan sehat. Dengan nilai korelasi pearson sebesar 0,878 sehingga di interpretasikan bahwa hubungan antara keduanya adalah kuat.

\section{Catatan Akhir}

Berdasarkan hasil penelitian mengenai Hubungan pemahaman materi Thaharah dengan kebiasaan PHBS dapat disimpulkan sebagai berikut :

1. Pemahaman siswa mengenai materi Thaharah di MTs Darul Muttaqien dapat dikatakan memuaskan. Hal ini dilihat melalui data variabel X (Pemahaman materi Thaharah) yang menunjukan nilai rata-rata tes sebesar 80 dengan nilai maksimum sebesar 93. 
2. Penerapan PHBS siswa di MTs Darul Muttaqien dapat dikatakan memuaskan. Hal ini dilihat dari data angket variabel y mengenai Kebiasaan Perilaku Hidup Bersih dan Sehat dengan skor rata-rata 57,8 dengan nilai maksimal 65.

3. Berdasarkan pengujian melalui korelasi pearson diketahui nilai sig. (2-tailed) sebesar $0,0000<0,05$ sehingga dapat disimpulkan terdapat hubungan yang signifikan antara Pemahaman materi Thaharah dengan kebiasaan perilaku hidup bersih dan sehat. Dengan nilai korelasi pearson sebesar 0,878 sehingga di interpretasikan bahwa hubungan antara keduanya adalah kuat.

Saran yang dapat peneliti berikan bagi guru adalah agar selalu mengingatkan siswa untuk menerapkan materi thaharah di dalam kehidupan sehari-hari. Sementara, untuk siswa adalah selain meningkatkan materi thaharah juga harus meningkatkan pola hidup bersih dan sehat dalam kehidupan sehari-hari. Dan saran untuk masyarakat adalah agar lebih mendalami pembahasan tentang thaharah dengan tujuan terciptanya perilaku hidup bersih dan sehat di lingkungan masyarakat.

\section{Daftar Rujukan}

Ahmad Mujahid, Haeriyyah. (2019). Thaharah lahir dan batin dalam Al-Qur'an. Jurnal AlRisalah, 19(2), 198-207.

Ahmad, M. S. (2014). Thaharah makna zawahir dan bawathin dalam bersuci. Mizan: Jurnal Ilmu Syariah, 2(1), 57-82.

Al-Mahfani, M. Kholilurrahman; Hamdi, Abdurrahim. (2016). Kitab Lengkap Panduan Shalat. Jakarta: Wahyu Qolbu.

Andriansyah, Y. (2013). Penyuluhan dan Praktik PHBS dalam Mewujudkan Masyarakat Desa Peduli Sehat. Jurnal Inovasi dan Kewirausabaan, 46.

Dkk, A. (2017). PHBS Pada Siswa-Siswi SDK Rita Pada Kecamatan Kota Komba Kabupaten Manggarai Timur Provinsi Nusa Tenggara Timur. Al-Sihab: Public Health Science Journal, 9(2), 187.

Julianti, R. (2018). Pelaksanaan PHBS di Lingkungan Sekolah. Jurnal Ilmiah Potensia , 3(2), 13.

Lina, H. P. (2016). Perilaku Hidup Bersih dan Sehat Siswa di SDN 42 Korong Gadang Kecamatan Kuranji Padang . Jurnal Promkes, 4(1), 92-103.

M. Said Alamsyah, Rinanda Purba. (2020). Meningkatkan Minat Belajar Thaharah dalam membersihkan najis dan hadas untuk tingkat Mts dengan media pop up book. Jurnal FSD, 1(1), 117-132.

Sugiyono. (2016). Metode Penelitian Kuantitatif, Kualitatif dan R\&D. Bandung: Alfabeta.

Tanjung, N. (2016). Hubungan Pengetahuan dan Sikap Siswa Tentang Perilaku Hidup Bersih dan Sehat Dengan Tindakan PHBS di SD Swasta Luther Kecamatan Siatas Barita Tapanuli Utara Tahun 2013. Jurnal Mutiara Kesehatan Masyarakat, 1(1), 43-52.

Tim Field Fakultas Kedokteran UNS. (2013). Komunikasi Informasi Edukasi PHBS. Surakarta: Fakultsa Kedokteran Universitas Sebelas Maret. 